\title{
Endogenous and Exogenous CD1-Binding Glycolipids
}

\author{
Janice M. H. Cheng, ${ }^{1,2}$ Ashna A. Khan, ${ }^{1,2}$ Mattie S. M. Timmer, ${ }^{1}$ and Bridget L. Stocker ${ }^{2}$ \\ ${ }^{1}$ School of Chemical and Physical Sciences, Victoria University of Wellington, P.O. Box 600, Wellington 6012, New Zealand \\ ${ }^{2}$ Malaghan Institute of Medical Research, P.O. Box 7060, Wellington 6242, New Zealand
}

Correspondence should be addressed to Mattie S. M. Timmer, mattie.timmer@vuw.ac.nz and

Bridget L. Stocker, bstocker@malaghan.org.nz

Received 15 August 2010; Revised 24 December 2010; Accepted 9 February 2011

Academic Editor: Yuriy A. Knirel

Copyright (C) 2011 Janice M. H. Cheng et al. This is an open access article distributed under the Creative Commons Attribution License, which permits unrestricted use, distribution, and reproduction in any medium, provided the original work is properly cited.

\begin{abstract}
In the same way that peptide antigens are presented by major histocompatibility complex (MHC) molecules, glycolipid antigens can also activate the immune response via binding to CD1 proteins on antigen-presenting cells (APCs) and stimulate CD1restricted T cells. In humans, there are five members of the CD1 family, termed CD1a-e, of which CD1a-d are involved in glycolipid presentation at the cell surface, while CD1e is involved in the intracellular trafficking of glycolipid antigens. Both endogenous (self-derived) and exogenous (non-self-derived) glycolipids have been shown to bind to members of the CD1 family with varying degrees of specificity. In this paper we focus on the key glycolipids that bind to the different members of the CD1 family.
\end{abstract}

\section{Introduction}

Carbohydrates play an important role in various molecular recognition events. They are found on the surfaces of cells, bacteria, and viruses as glycoconjugates (such as glycoproteins and glycolipids), and it is therefore not surprising that their interaction with cells of the immune system forms an integral part of the body's immune response. The innate immune system operates largely via receptor-ligand interactions, and glycoconjugates are capable of inducing the strongest immune responses known. Classic examples include the landmark discovery of endotoxin by Pfeiffer in the late 19th century [1] and the discovery in 1928 by Landsteiner and Levine that blood group determinants were responsible for the blood cell rejection (also known as transfusion reaction) observed during blood transfusion with incompatible donors [2]. Only later was it revealed that endotoxin is in fact a glycolipid [3] and that the A, B, and O antigens responsible for transfusion reaction are glycolipids and glycoproteins found on the surface of red blood cells [4].

Recently, cell-mediated immunity to glycolipid antigens has been discovered, and a glycolipid presentation pathway which parallels that of peptide antigen presentation has emerged. The glycolipid pathway involves CD1 proteins, major histocompatibility complex- (MHC-) like molecules that are capable of presenting glycolipids to a specialised subset of CD1-restricted T cells. Like MHC molecules, CD1 proteins are present on antigen-presenting cells (APCs), specialised immune cells that perform a crucial role in the immune system. After encountering an antigen, the APC sends messages to other immune cells, subsequently activating the full immune response. This paper will focus on CD1-binding glycolipids that are capable of activating and modulating the immune system via the activation of CD1restricted T cells.

\section{CD1 Molecules}

The $\mathrm{CD} 1$ protein is a transmembrane glycoprotein consisting of a heavy chain with three extracellular domains $(\alpha 1, \alpha 2$, and $\alpha 3)$ noncovalently linked to a $\beta_{2}$-microglobulin $\left(\beta_{2} \mathrm{~m}\right)$ chain (Figure 1) [5]. The nonpolar amino acids in the $\alpha 1$ and $\alpha 2$ chains form the hydrophobic pockets that can accommodate the long lipid tails of a glycolipid. The CD1 family contains five members, CD1a, CD1b, CD1c, CD1d, and CD1e, which, depending on their sequence homology, can be further classified into three groups: group 1 (CD1a, CD1b, and CD1c), group 2 (CD1d), and group 3 (CD1e). In a CD1glycolipid complex (Figure 1), the polar carbohydrate group 


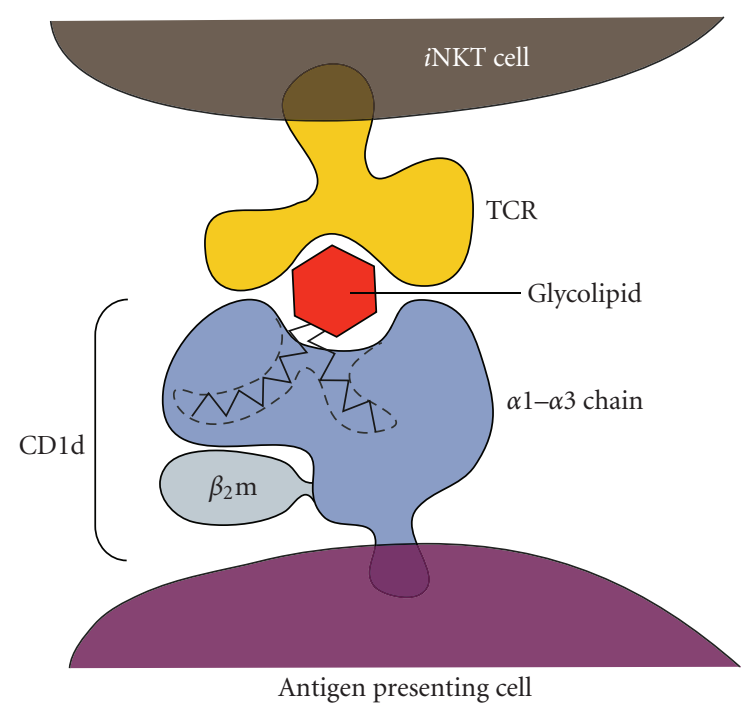

FIGURE 1: Representation of CD1-glycolipid-TCR interaction during glycolipid antigen presentation.

of the glycolipid protrudes from the CD1 binding groove, allowing it to be recognised by CD1-restricted $\mathrm{T}$ cells via the $\mathrm{T}$ cell receptor (TCR). The trimolecular interaction between CD1, glycolipid, and TCR initiates a cascade of intracellular signalling that activates the $\mathrm{T}$ cells to produce signalling molecules called cytokines. The type of immune response generated is dependent on the cytokine profile produced.

The exact effect that the glycolipid molecular structure has on the immune response is only known in a very general sense. Unlike MHCs, which specifically bind peptide antigens, CD1 molecules accommodate structurally diverse glycolipids. Extensive crystal structure analysis of CD1 molecules with bound ligands suggests that CD1 binding is less specific, which supports the observation that the length of a lipid tail does not greatly affect the immunomodulatory profile of a given glycolipid [6]. Instead, the highly specific interaction of the TCR with the CD1-glycolipid complex plays the principal role in dictating the outcome of the immune response $[7,8]$. Other processes such as CD1 and glycolipid trafficking into the cell and glycolipid processing prior to TCR recognition have also been found to have a profound effect on the immune response [9-11]. The ability of glycolipids to modulate the immune response prompted researchers to develop specific CD1-binding glycolipids that can be used in the investigation and treatment of many diseases, including cancer, bacterial infections, and autoimmune diseases such as multiple sclerosis and systemic lupus.

\section{Endogenous and Exogenous Glycolipids}

Production of antigen-specific $\mathrm{T}$ cells requires positive selection in the thymus. For the glycolipid reactive CD1-restricted $\mathrm{T}$ cells, this means that endogenous glycolipids, originating from within the host organism, must be presented by CD1 proteins and interact with the TCRs of developing CD1-restricted T cells. Isoglobotrihexosylceramide (iGb3) is the most studied endogenous glycolipid and has been suggested to be the pivotal ligand for the selection of CD1drestricted $\mathrm{T}$ cells in the thymus [12], though further investigations are required to support this hypothesis [13]. Other endogenous glycolipids such as gangliosides and sulfatide, as well as phosphoglycerolipids and sphingomyelin, have also been found to stimulate group $1 \mathrm{CD} 1$-restricted T cells. The exact role that endogenous lipids have in the activation of CD1-restricted T cells, however, remains unclear.

Of the exogenous glycolipids, numerous bacterial cell wall glycolipids have been shown to play an important role in the immune response. In particular, the discovery that mycolic acid, a nonpeptide lipid antigen from Mycobacterium tuberculosis $(M . T b)$, stimulates $T$ cells via CD1 molecules paved the way towards the discovery of a host of glycolipids that activate the immune system in a similar manner [14]. Subsequently, other glycolipid cell wall components of $M$. $T b$, such as glucose monomycolate (GMM) [14], phosphatidylinositolmannoside (PIM) [15], and lipoarabinomannan [16], have also been found to be immunogenic [17]. However, not all bacterial glycolipids are responsible for the activation of the immune system during infection. Interestingly, Mattner et al. discovered that the antigen responsible for activating $\mathrm{CD} 1$-restricted $\mathrm{T}$ cells in mice during an infection with Gram-negative, LPS-positive Salmonella typhimurium, was in fact the endogenous glycolipid, iGb3 [18].

When comparing endogenous and exogenous CD1binding glycolipids, perhaps the most obvious structural difference is the linkage variation between the carbohydrate and the lipid backbone. Endogenous glycolipids such as iGb3 have $\beta$-linkages, while exogenous/pathogenic glycolipids (i.e., most bacterial glycolipids) typically have $\alpha$-linkages. In this paper, endogenous and exogenous CD1-binding glycolipids will be described in the context of the CD1 isotype with which they interact. The origin/discovery, synthesis, and effect on the immune response of each glycolipid will also be discussed.

3.1. CD1a. The human CD1a molecule possesses two hydrophobic pockets $\left(\mathrm{A}^{\prime}\right.$ and $\left.\mathrm{F}^{\prime}\right)$ that can bind aliphatic carbon chains of glycolipids via nonpolar Van der Waals interactions. The $\mathrm{A}^{\prime}$ pocket of CDla is narrow with only one entry point and hence has been proposed to be a "molecular ruler" that allows CD1a to bind $\mathrm{C}_{20}$ lipids or shorter [19]. The $\mathrm{F}^{\prime}$ pocket of $\mathrm{CD} 1 \mathrm{a}$ is also unique in that it lies close to the plane of TCR recognition and hence directly participates in antigen presentation [6].

3.1.1. Endogenous Glycolipids. Sulfatide, illustrated by $\mathbf{1}$ (Scheme 1), is a $\beta$-D-galactosylceramide sulfated at C-3 of Dgalactose. Ceramides are long chain dihydroxy or trihydroxy bases which are linked to a fatty acid via an amide linkage at C-2. The sphingosine base, a dihydroxylated base with mono-unsaturation across C-4 and C-5, is commonly found in endogenous glycolipids and forms the lipid backbone of sulfatides. Sulfatide is a potent glycolipid produced by mammalian cells and is found mainly in the myelin sheath but is also present in small amounts in other tissues [20]. 
The ability of sulfatide to bind to all group 1 and group 2 CD1 proteins (CD1a-d) gives it the just reputation of being the most promiscuous CD1-binding glycolipid [20, 21]. Nonetheless, its binding affinity differs with each CD1 isotype, with the CD1a-sulfatide complex seeming to be the most stable [20]. Here the narrow $\mathrm{A}^{\prime}$ pocket allows CD1a to selectively bind to the $\mathrm{C}_{18}$ sphingosine backbone while the acyl lipid protrudes along the surface of the CD1a molecule and extends into the $\mathrm{F}^{\prime}$ pocket. The 3-O-sulfogalactose protrudes from the CD1 pocket and interacts with the TCR of the T cell.

Elevated levels of sulfatide-reactive $\mathrm{T}$ cells in multiple sclerosis patients reveal that this endogenous glycolipid may be responsible, at least in part, for the pathogenesis of neurodegenerative diseases. The ability of the sulfatide glycolipid to stimulate CD1-restricted T cells has proven valuable in the understanding and treatment of autoimmune diseases of the central nervous system, particularly in multiple sclerosis.

With regard to their syntheses, several $\beta$-sulfatides with varying chain lengths and $\alpha$-analogues of sulfatides have been reported by Compostella et al. and Franchini et al., respectively $[22,23]$. The former employed a $\beta$-glycosylation of an azidosphingosine 2 with pivaloyl protected D-galactosyl trichloroacetimidate 3 as a key step (Scheme 1). After global deprotection of the coupled product 4 , the azide was reduced and the resulting amine derivatized with a fatty acid to obtain galactosyl ceramide $\mathbf{5}$. Regioselective 3 -sulfation of $\mathbf{5}$ then gave the desired sulfatide $\mathbf{1}$, in excellent overall yield.

3.2. CD1b. The CD1b isotype, found in humans but not in mice, has a binding groove with four pockets: $A^{\prime}, C^{\prime}, F^{\prime}$, and $\mathrm{T}^{\prime}$ [24]. The $\mathrm{T}^{\prime}$ tunnel, which connects the $\mathrm{A}^{\prime}$ and $\mathrm{F}^{\prime}$ pockets, is unique to CD1b and accounts for the ability of the combined binding pockets to accommodate long alkyl chains $\left(\sim \mathrm{C}_{68}\right)$. The extra $\mathrm{C}^{\prime}$ pocket, which is also only found in CD1b, contributes to the receptor's ability to host large bacterial antigens such as the sulfotrehalose and mycolyl antigens [25]. Similar to CD1a, nonpolar amino acids lining the interior of the binding pockets provide nonpolar Van der Waals interactions with the glycolipid lipid chains.

3.2.1. Endogenous Glycolipids. Gangliosides (e.g., GM1 (6) and GQ1b (7), Figure 2) are sialic acid containing glycosphingolipids and are constituents of the plasma membrane of various cells. Gangliosides are perhaps one of the largest classes of endogenous glycolipids, and autoreactivity of $\mathrm{T}$ cells or IgG autoantibodies to these gangliosides may be the cause of various immune-mediated diseases such as multiple sclerosis, rheumatoid arthritis, lupus erythematosus, and psoriasis [26]. In all gangliosides, the ceramide is linked via $\mathrm{C}-1$ to a $\beta$-O-glucose moiety, which in turn is glycosylated at the $4-\mathrm{OH}$ with a $\beta-O$-galactosyl residue. The structural diversity of gangliosides results from further glycosylation of this disaccharide.

GM1 (6, Figure 2) is the most abundant ganglioside found in the human myelin sheath and consists of a ceramide with a core tetrasaccharide to which a single sialic acid residue is attached. GM1 binds to CD1b on the cell surface at neutral $\mathrm{pH}$ and is recognised without internalisation and processing [27]. These CD1b-GM1 complexes can stimulate $\mathrm{T}$ cells to induce a T-helper 1- (Th1-) type response measured by the release of cytokines such as TNF- $\alpha$ and IFN- $\gamma$, which are important cytokines for the generation of a cytotoxic immune response [27]. Ganglioside-specific T cells can discriminate small differences in the carbohydrate portion of the glycolipid as revealed by a study whereby analogues of GM1 that lack the terminal galactose residue (GM2), sialic acid residue (asialo-GM1), or both were unable to stimulate production of IFN- $\gamma$ by $\mathrm{T}$ cells [27]. This suggests that the GM1 pentasaccharide represents the minimum epitope for recognition by TCRs. The structure of the lipid tail and the fatty acid is also important for the specificity of CD1b binding, with stearic acid having the highest $\mathrm{T}$ cell stimulatory capacity [27]. GM1 binding to CD1b is highly reversible, and other ceramide-containing glycosphingolipids can displace GM1 in the CD1b complex. The first total synthesis of GM1 occurred in 1986 by Sugimoto et al. and took an impressive twelve linear steps [28]. From the retrosynthesis (Scheme 2), it can be seen that the main steps involved the coupling of the peracetylated pentasaccharide imidate $\mathbf{8}$ to sphingosine acceptor $\mathbf{9}$, which was accomplished in $33 \%$ yield using $\mathrm{BF}_{3} \cdot \mathrm{Et}_{2} \mathrm{O}$ as the activator. Donor $\mathbf{8}$ in turn was accessible via coupling of galactosyl galactosamine $\mathbf{1 0}$ and sialylated lactoside $\mathbf{1 1}$.

More recently, the methyl glycoside of GM1 has been synthesised by Bhattacharya and Danishefsky along with the asialo GM1 analogue [29]. The study of the binding of GM1 and its analogues to CD1b and the subsequent activation of ganglioside-specific T cells will aid in the understanding of the autoimmune disease multiple sclerosis as it was found that gangliosides are present in increased frequencies in patients with this disease [30].

GQ1b (7, Figure 2) is another ganglioside that binds to CD1b and stimulates CD1-restricted T cells [31]. It was first isolated from the human brain in 1963 and later characterised in 1979 [32-34]. GQ1b consists of the core ganglioside tetrasaccharide to which four sialic acid residues are connected. Similar to other endogenous glycolipids, the ceramide contains the sphingosine backbone. GQ1b is most abundant in the mammalian central nervous system and participates in physiological activities such as toxin binding, modulation of protein phosphorylation, cell adhesion and growth, and apoptosis $[35,36]$. GQ1b binds to CD1b molecules and, upon binding to the T cell TCR, induces the production of the Th1 cytokines IL- 2 and IFN- $\gamma$ while suppressing Th2 cytokine production [37]. While this suggests that perturbation of GQ1b levels may lead to a Th1/Th2 imbalance, elevated or suppressed levels of GQ1b have yet to be correlated with diseases resulting from this immunological imbalance [37]. Total synthesis of GQ1b has been accomplished by Ishida and coworkers in 1994 [31] and more recently by Imamura and colleagues in 2009 [35]. Ishida and coworkers used trimethylsilyloxyethyl (SE) protected octasaccharide $\mathbf{1 2}$ (Figure 3 ) to produce imidate donor 13, which could be efficiently coupled to azide acceptor 2 (using TMSOTf and in $46 \%$ yield), en route to GQ1b. 


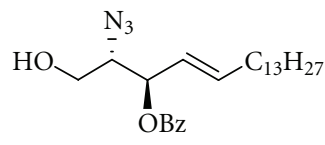

2

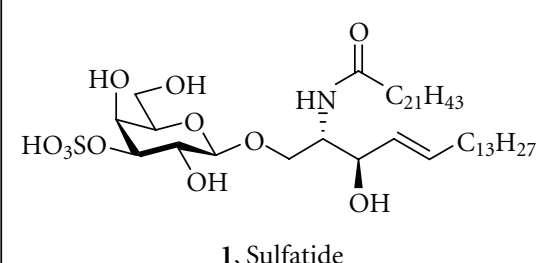

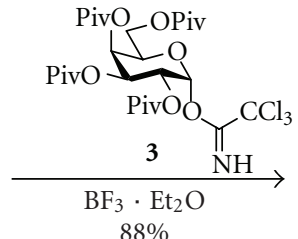

(1) $\mathrm{Bu}_{2} \mathrm{SnO}, \mathrm{MeOH}, \Delta$

(2) $\mathrm{Me}_{3} \mathrm{~N} \cdot \mathrm{SO}_{3}, \mathrm{THF}, \mathrm{rt}$ $75 \%$

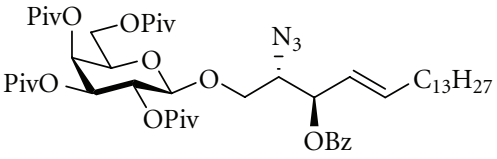

4

(1) $\mathrm{NaOMe}, \mathrm{MeOH}$

(2) $\mathrm{H}_{2} \mathrm{~S}$, pyridine, $\mathrm{H}_{2} \mathrm{O}, 76 \%$

$\downarrow$ (3) $\mathrm{ClC}(\mathrm{O}) \mathrm{C}_{21} \mathrm{H}_{43}, \mathrm{NaOAc}, 71 \%$

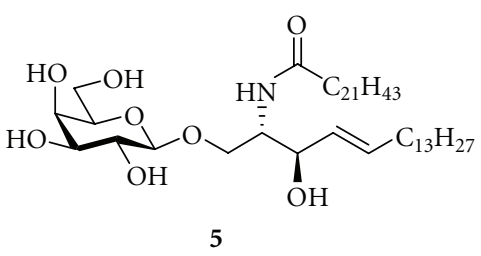

Scheme 1: Representative synthesis of a sulfatide.

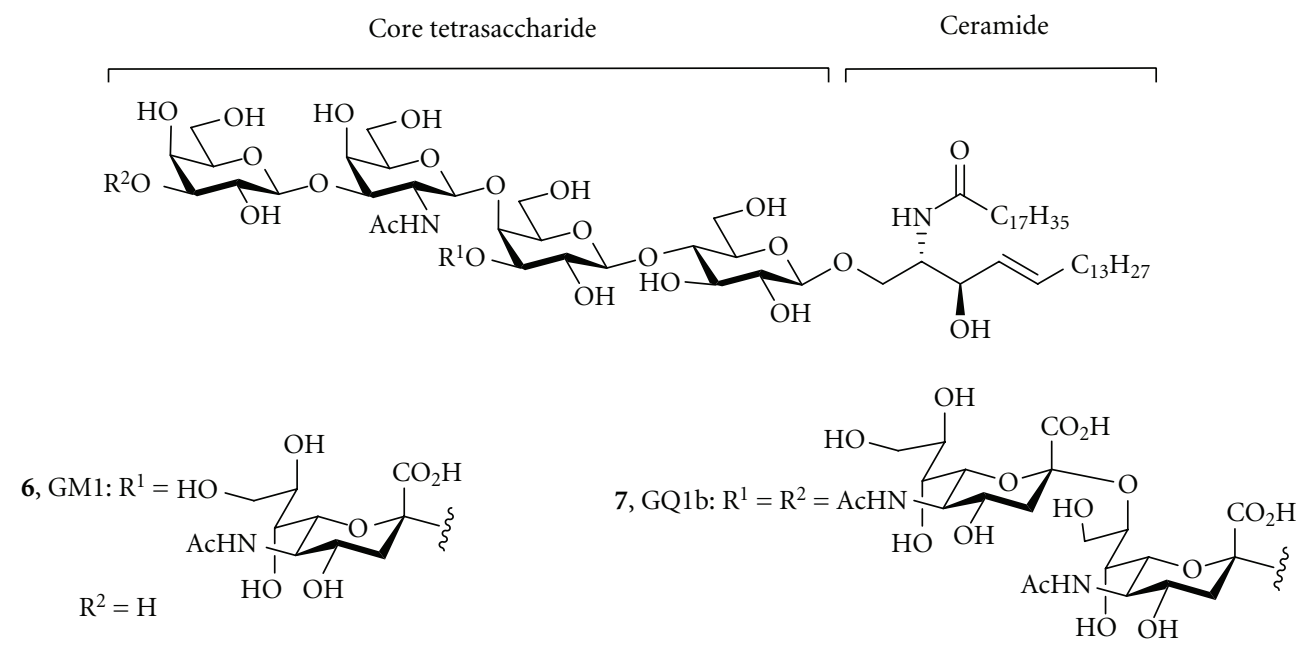

Figure 2: Gangliosides GM1 and GQ1b.

\subsubsection{Exogenous Glycolipids. Glucose-monomycolate} (GMM, 14, Figure 4) is the 6-O-mycolate ester of D-glucose and is found in bacterial species including Mycobacteria, Rhodococcus, and Nocardia. Mycolic acids themselves are $\alpha$-alkyl, $\beta$-hydroxy fatty acids that are present in most mycobacterium species and also in related taxa. Mycolic acids from different species of bacteria may vary to give rise to alpha-, keto-, methoxy-, or epoxy-mycolic acids. The GMM (14) illustrated contains the alpha-mycolic acid backbone. It should also be noted that mycolic acids were the first lipid antigens revealed to activate CD1-restricted T cells via binding to CD1b molecules [14].

GMM is a potent ligand for CD1-restricted T cells when presented by CD1 molecules [7]. For example, studies have shown that the CD1b-restricted T-cell recognition of GMM is highly specific for the glucose moiety since naturally occurring mycolate esters of glycerol and arabinose are not recognised by CD1-restricted T cells. In addition, the $R, R$ configuration of the hydroxy acid and the position of the linkage of the mycolate to the glucose unit are also important for CD1 binding [7]. Structural and mass-spectroscopy analysis has shown that high-affinity binding also depends on the exact structure of the acyl side chains of the antigen [38]. Crystal structure studies of the CD1b-GMM complex indicate that both acyl chains are buried in the antigen binding groove of CD1b, thus leaving the glucose unit exposed to the surface for recognition by TCRs. This explains the observation that one TCR can recognise GMMs with varying chain lengths derived from different bacterial sources [39].

Diacylated trehalose sulphates ( $\mathrm{Acyl}_{2} \mathrm{SGL}, 15$, Figure 5) are lipid antigens produced by virulent $M$. $T b$ and consist of a trehalose core that is acylated at the 2-position by palmitic (or stearic) acid and acylated at the 3-position by 

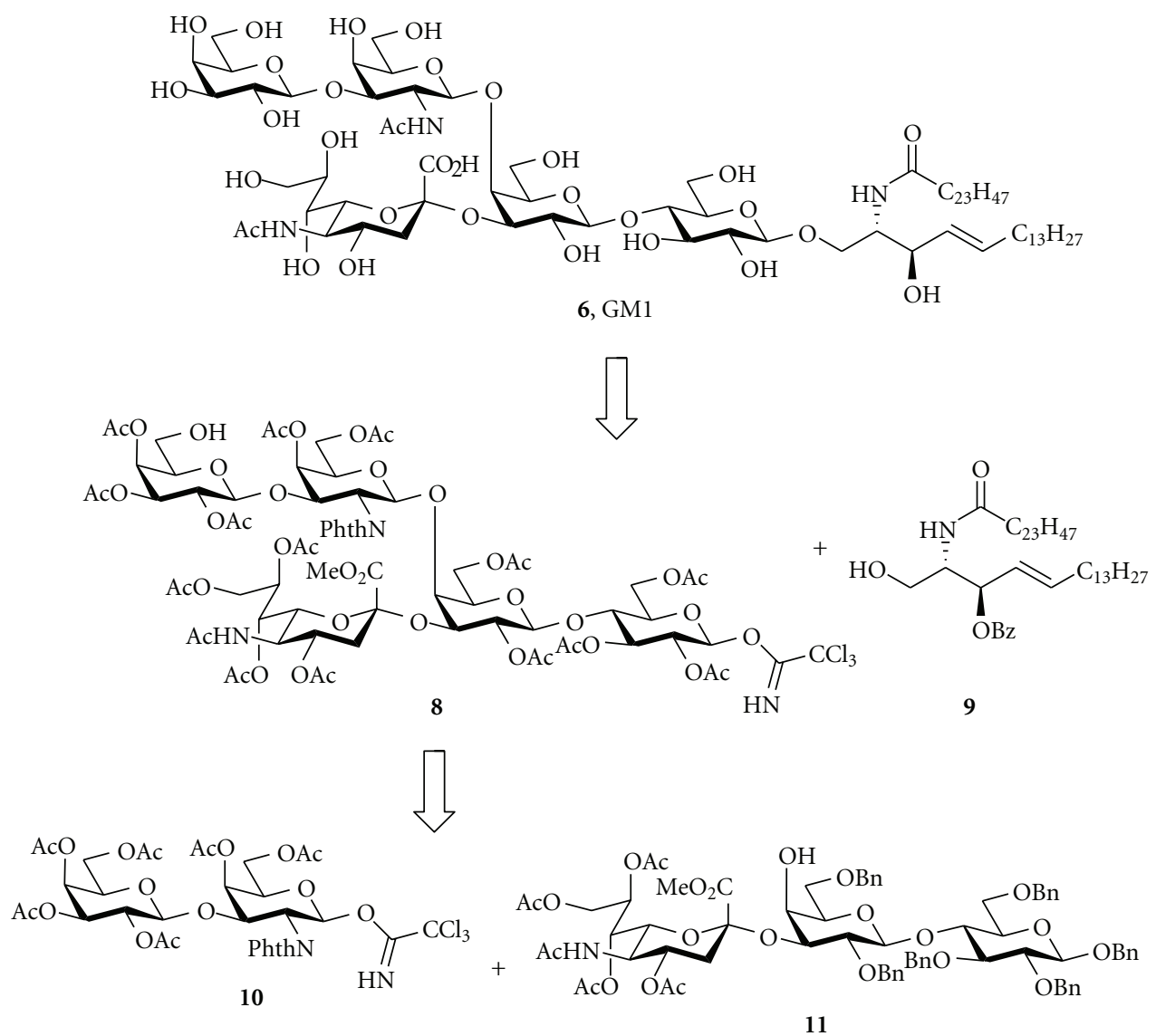

Scheme 2: Synthesis of GM1.

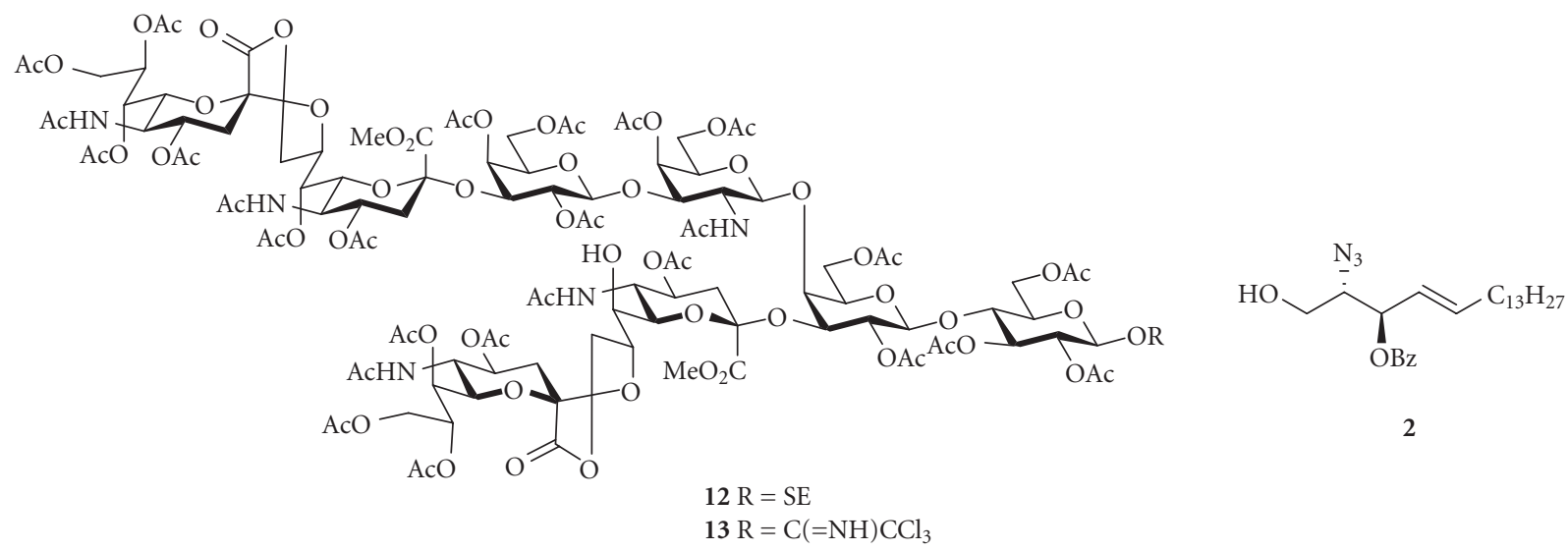

FIGURE 3: Building blocks for the synthesis of GQ1b.

hydroxyphthioceranoic acid [40]. While the methyl branches were assigned to be of the $L$-series, the stereochemistry of the hydroxy-substituted carbon has not been assigned [41].

Sulfoglycolipids bind to human CD1b, stimulate CD1brestricted T cells to release the cytotoxic cytokine IFN- $\gamma$, and recognise $M$. $T b$-infected cells in a host, leading to killing of intracellular bacteria [40]. The influence that the lipid chains have on $\mathrm{T}$ cell activation in relation to the length, position, and structure of the fatty acid residues has been studied, and it was observed that the presence and stereochemistry of a multimethyl-branched fatty acid appendage on the 3position in $\mathrm{Acyl}_{2} \mathrm{SGL}$ were crucial for T cell stimulation [42]. Naturally occurring $\mathrm{Acyl}_{2} \mathrm{SGL}$, illustrated in $\mathbf{1 5}$, was seen to be most potent in T-cell activation as revealed in a study by Guiard and coworkers, who synthesised a range of sulfoglycolipid analogues in which the hydroxyphthioceranoic acid has been replaced by less complex acids (Scheme 3 ) [42]. The synthesis started with the selective acylation of the 


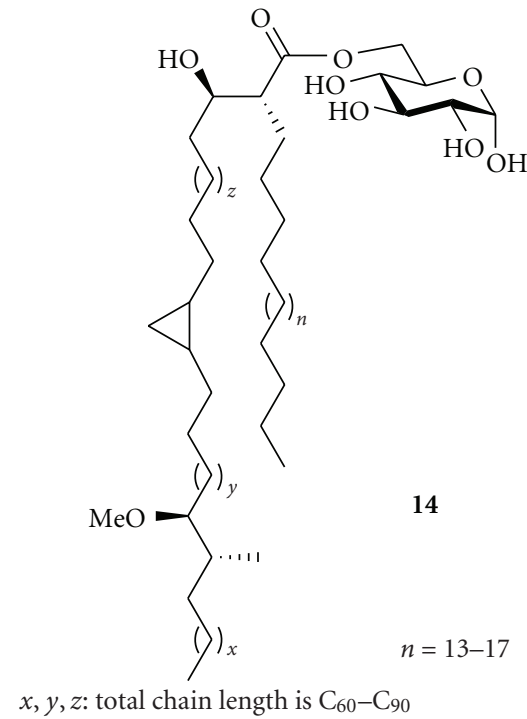

FIGURE 4: Representative glucose monomycolate (GMM).

readily available $4,6: 4^{\prime}, 6^{\prime}$-di-O-benzylidene protected $\alpha, \alpha^{\prime}$ trehalose 16, which gave the $2-O-$ acyl product 17 without the need for stannylene chemistry or elaborate protecting group manipulations. Subsequent protection of the diol in 17 with dichloro-tetraisopropyldisiloxane gave alcohol 18 which was then acylated at the 3-position with various long chain branched fatty acids. Finally, the siloxane protection in 19 was removed using TBAF and the resulting diol 20 selectively sulphated at the $2^{\prime}$-position to gain sulphate 21. Final deprotection using catalytic acid provided the SGL analogues (e.g., 22). Although none of the synthetic compounds were as potent as the natural sulfoglycolipid 15, some of the sulfoglycolipid analogues showed promising Tlymphocyte-activation properties [42]. It was later shown that the presence of $\mathrm{T}$ cells that can recognise $\mathrm{Acyl}_{2} \mathrm{SGL}$, in patients with active or latent tuberculosis, demonstrates the potential of sulfoglycolipids as subunit vaccine against tuberculosis [43].

3.3. CD1c. To date, there is no high-resolution structural data for $\mathrm{CD} 1 \mathrm{c}$, but computational studies of the protein in complex with a $M$. $T b$ glycolipid, mannosyl- $\beta 1-$ phosphomycoketide (MPM), indicate that the enlarged $\mathrm{F}^{\prime}$ pocket can accommodate bacterial polyketides with multiply branched unsaturated alkyl tails [44]. From the structural model of CD1c with phosphomycoketide, it was hypothesised that the $\mathrm{A}^{\prime}$ pocket does not contribute much to the specificity of the CD1c binding domain as it is similar to the $\mathrm{A}^{\prime}$ pocket of $\mathrm{CD} 1 \mathrm{~b}$ and $\mathrm{CD} 1 \mathrm{~d}$. Moreover, CD1c is set apart from other members of the CD1 family due to its unusual ability to present glycolipids that only have a single lipid tail.

3.3.1. Endogenous Glycolipids. Mannosyl- $\beta$-1-phosphodolichol (MPD, 23, Figure 6) belongs to the family of glycosyl1-phosphopolyprenols that are found in all cells [45]. They function as sugar donors in the glycan biosynthesis pathways of eukaryotes and bacteria and are important for cell-wall assembly in prokaryotes. The length, saturation, phosphorylation, and glycosylation of the isoprenoid backbones vary in different organisms. Multicellular organisms have the longest $\left(\mathrm{C}_{90-100}\right)$ dolichols, while fungi and protozoa have shorter chain lengths $\left(C_{70-90}\right.$ and $C_{50-65}$, resp.) $[46,47]$.

MPD consists of a mannoside $\beta$-linked to a phosphopolyprenoid lipid via a phosphate group. Except for the proximal isoprene, the lipid contains unsaturated isoprene units linked in trans and cis configurations. The ability of $\mathrm{CD} 1 \mathrm{c}$, but not other $\mathrm{CD} 1$ proteins, to accommodate methyl branching within a single lipid indicates the specificity of CD1c for this branched motif [45].

Through the testing of various isolated and semisynthetic MPD analogues, a correlation between dolichol chain length and T-cell response has been observed. MPDs with a chain length similar to those found in Mycobacteria $\left(\mathrm{C}_{30-35}\right)$ gave the strongest $\mathrm{T}$-cell responses, while no activation was observed for lipids with longer chains $\left(\mathrm{C}_{55-95}\right)$ [45]. This is probably because long lipid chains resemble the endogenously expressed MPD, which should not generate any immune response in the absence of infection and illustrates the capability of $\mathrm{CD} 1 \mathrm{c}$ to distinguish between selflike and foreign-like glycolipids.

3.3.2. Exogenous Glycolipids. Mannosyl- $\beta$-1-phosphomycoketides (MPMs, 24, Figure 7) are potent mycobacterial antigens recently isolated from Mycobacterium avium (24a) and Mycobacterium tuberculosis (24b) [44]. These phospholipids consist of a mannosyl- $\beta$-phosphate moiety similar to that in the endogenous MPD (23) but possess an unusual saturated isoprenoid backbone. The antigenicity of the MPM is largely attributed to the saturation of the lipid chain and the shorter length of the backbone $\left(\mathrm{C}_{30}\right)$ as compared to their endogenous dolichol counterparts [48]. Like MPDs, the methyl branches ( $S$-configuration) of this mannosyl- $\beta$ 1-phosphomycoketide help retain the lipid in the $\mathrm{F}^{\prime}$ pocket, thus allowing for T-cell recognition and activation [49]. The synthesis of MPM 24a was first reported by Crich and Dudkin in 2002 [50], and, more recently, MPM 24b and analogues thereof were synthesised by Van Summeren and coworkers [51]. Crich and Dudkin (Scheme 4(a)) used a strategy whereby triflate donor $\mathbf{2 5}$ was coupled to the isoprenoid phosphate $\mathbf{2 6}$ to give mannosyl phosphate 27 which could be deprotected in a single Birch reduction to provide MPM 24a. Van Summeren and coworkers, however, phosphorylated tetraacetylmannose $\mathbf{2 8}$ to give phosphate triester 29 (Scheme 4(b)). After deprotection of 29, phosphate 30 was coupled to isoprenoid alcohol 31 to give phosphodiester 32. Final deacetylation then gave MPM 24b. These syntheses not only confirmed the structural identification of these naturally occurring MPMs lipids but also assist in the development of a subunit vaccine against tuberculosis [52].

3.4. CD1d. CD1d is perhaps the most widely studied CD1 protein due to its structural homology across mice and humans [6] and its importance in cancer immunotherapy. 


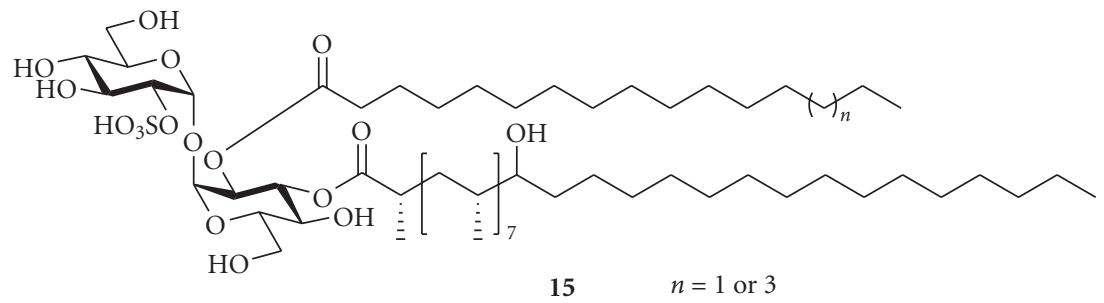

FIgUre 5: Diacylated trehalose sulphate ( $\left.\mathrm{Acyl}_{2} \mathrm{SGL}\right)$.

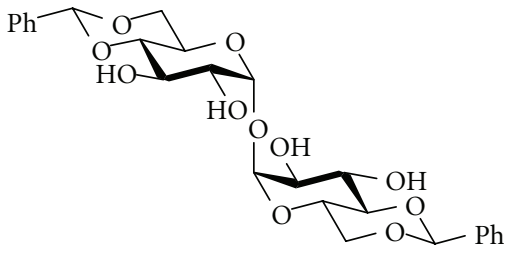

16

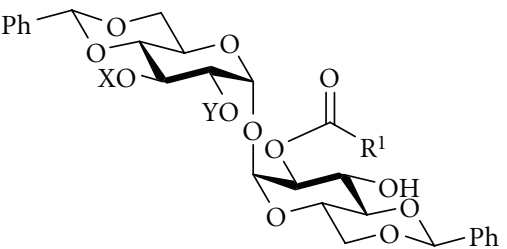

TIPSCl $_{2}-17 \mathrm{X}=\mathrm{Y}=\mathrm{H}$

pyridine $\longrightarrow 18 \mathrm{X}, \mathrm{Y}=-i \mathrm{Pr}_{2} \mathrm{Si}-\mathrm{O}-i \mathrm{Pr}_{2} \mathrm{Si}-$ $60 \%$

$\mathrm{R}^{2} \mathrm{C}(\mathrm{O}) \mathrm{Cl}$ pyridine, DMAP $\downarrow 26-54 \%$

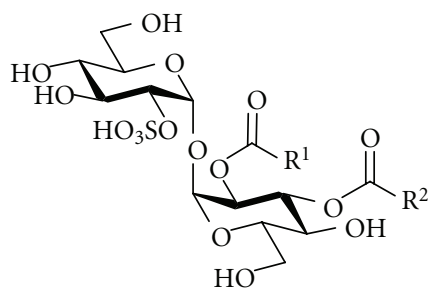

$\overleftarrow{\mathrm{H}_{2} \mathrm{SO}_{4}}$

$\mathrm{Ph}$

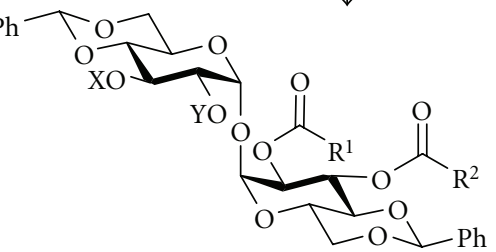

TBAF $19 \mathrm{X}, \mathrm{Y}=-i \mathrm{Pr}_{2} \mathrm{Si}-\mathrm{O}-i \mathrm{Pr}_{2} \mathrm{Si}-$ e.g. $\mathrm{R}^{1}=\mathrm{C}_{15} \mathrm{H}_{31}$

$\mathrm{R}^{2}=\mathrm{C}_{\bar{\vdots}} \mathrm{C}_{15} \mathrm{H}_{31}$

Scheme 3: Synthesis of Acyl 2 SGL analogues.

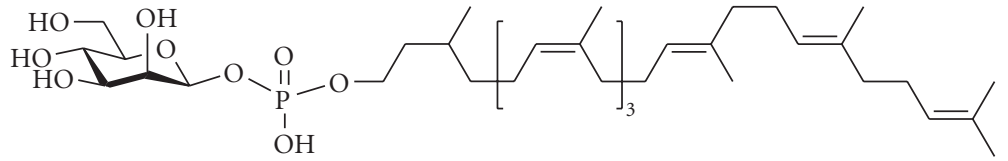

23

FIgURe 6: Mannosyl- $\beta$-1-phosphodolichol (MPD).

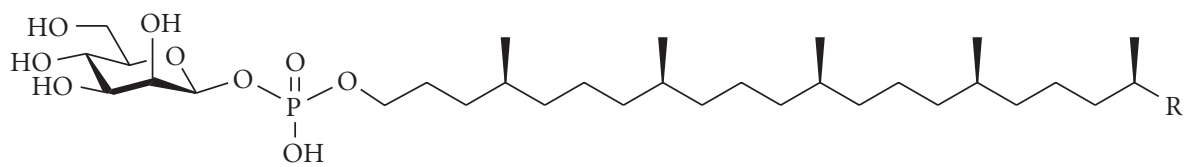

24a $\mathrm{R}=\mathrm{C}_{5} \mathrm{H}_{11}$ (M. avium)

24b R $=\mathrm{C}_{7} \mathrm{H}_{15}$ (M. tuberculosis)

FIgURE 7: Mannosyl- $\beta$-1-phosphomycoketide (MPM). 


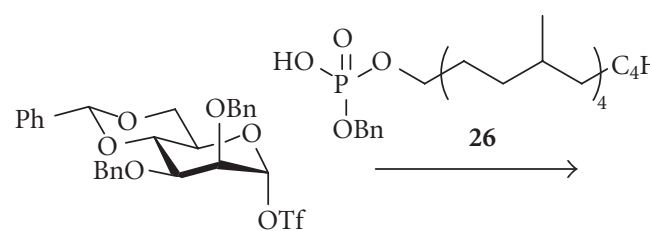

25

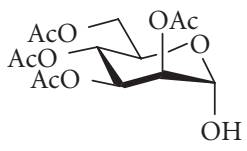

28

$24 b$

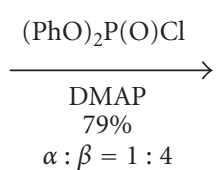

$\alpha: \beta=1: 4$

(a)

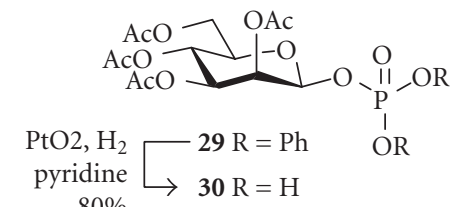

$80 \%$
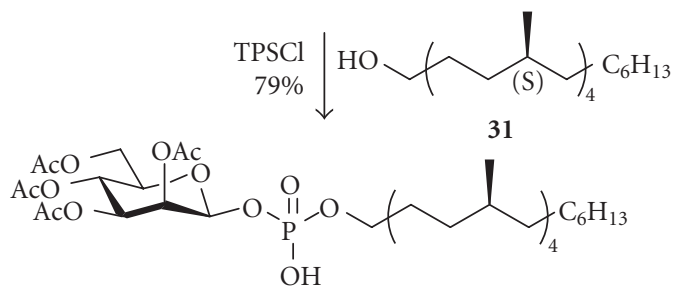

32

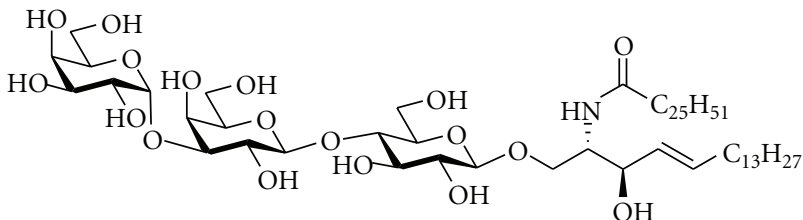

33a, iGb3

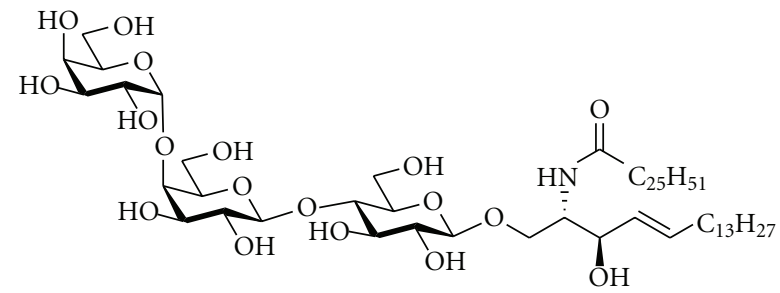

33b, Gb3

FIgUre 8: iGb3 and Gb3.

The heavy $\alpha$ chains form the hydrophobic binding pockets $\mathrm{A}^{\prime}$ and $\mathrm{F}^{\prime}$ that are able to accommodate lipid tails of glycolipids, as illustrated by the crystal structure of CD1d bound to $\alpha$ galactosyl ceramide [53]. An extensive hydrogen bonding network holds the sugar head group in place for recognition by the $\mathrm{T}$ cell receptor.

3.4.1. Endogenous Glycolipids. Isoglobotrihexosylceramide (iGb3, 33, Figure 8) is a triglycosylceramide with a lactose residue $\beta$-linked to a ceramide with a sphingosine backbone and a terminal galactose residue, bound via an $\alpha(1-3)$ linkage to the nonreducing end of the lactosylceramide. iGb3 can be isolated from cat intestines but has also been chemically [54] and enzymatically [10] synthesised. Interestingly, iGb3 has been shown to play an important role in the clearing of bacterial infections [12]. This was illustrated in a study whereby mice, lacking in an enzyme that converts the biological precursor iGb4 to iGb3, were found to be deficient in CD1d-restricted $\mathrm{T}$ cells and subsequently incapable of clearing infection by Salmonella typhimurium. Also of note is that the globoside Gb3, which contains an $\alpha(1-4)$-linked terminal galactose instead of the $\alpha(1-3)$ linkage in iGb3, does not stimulate CD1-restricted T cells [55]. This indicates that 


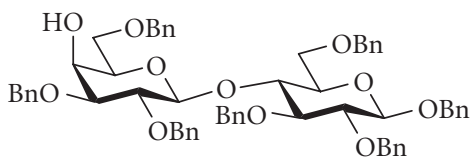

34

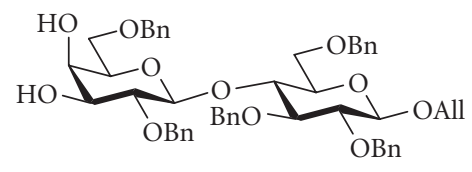

37

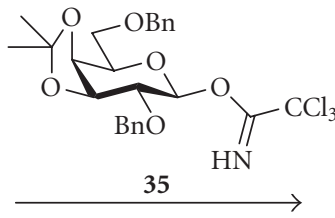

TMSOTf, $-20^{\circ} \mathrm{C}$ $79 \%$ $\alpha: \beta=6: 1$

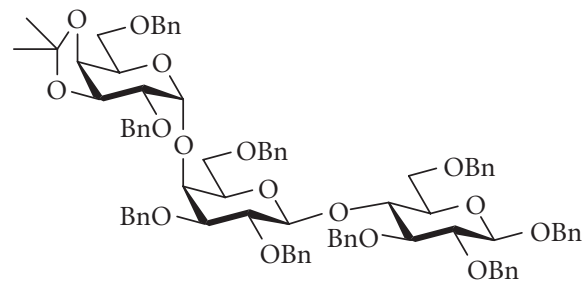

36

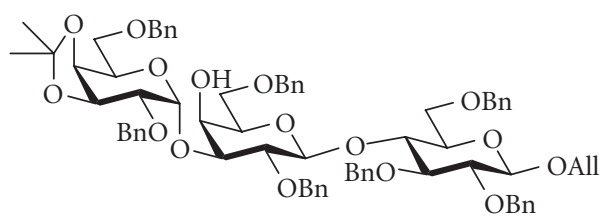

38

Scheme 5: Synthesis of globoside trisaccharides.

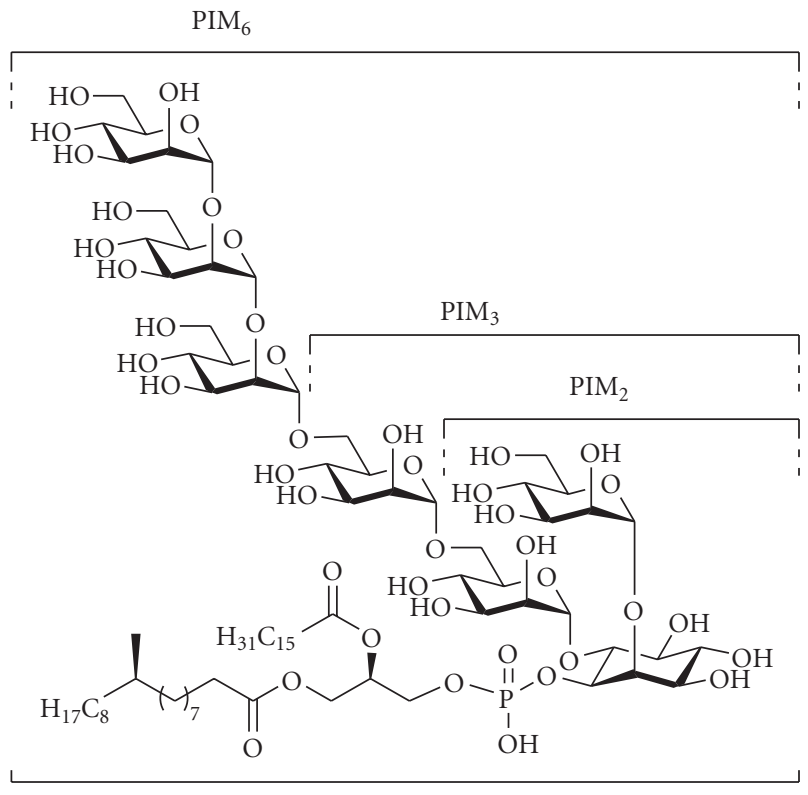

Phosphatidyl-myo-inositol (PI)

39, PIMs

FIGURE 9: Phosphatidylinositolmannosides (PIMs).

there is a high level of specificity for the interaction between CD1d-glycolipid complexes with the TCRs of CD1-restricted T cells.

Qiu and Schmidt provided convenient routes for the synthesis of globosides (Scheme 5) [54]. Here, glycosylation of lactose acceptor 34 with imidate 35 provided the isogloboside trisaccharide 36 , while regioselective glycosylation of lactose acceptor 37 with the same donor provided the isomeric trisaccharide 38. The total syntheses of iGb3 and Gb3 were finalised by transforming 36 and 38 into their respective imidates, coupling to a sphingosine acceptor (cf. 2, Scheme 1) and deprotection/acylation.

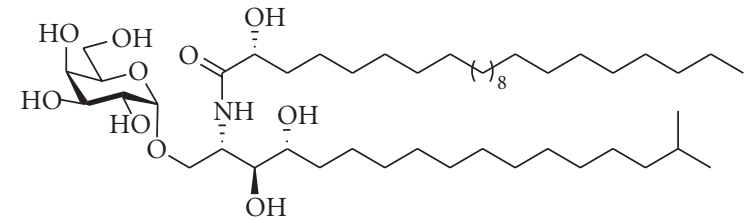

43a, AGL-9b

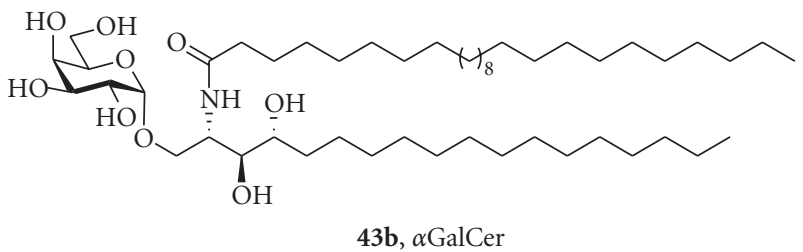

Figure 10: Agelasphin-9b (AGL-9b) and $\alpha$-galactosyl ceramide ( $\alpha$ GalCer).

Sulfatide (cf. 1, Scheme 1). As previously mentioned, sulfatide binds to all members of the CD1 family. In the case of CD1d, Shamshiev and coworkers found that the presence of the 3-O-sulfate group as well as the $\beta$-anomeric linkage was crucial for the activation of CD1d-restricted T cells [20].

3.4.2. Exogenous Glycolipids. Phosphatidylinositolmannosides (PIMs, 39, Figure 9) were first isolated from $M$. Tb in 1930 [56] and shown to be a natural antigen for CD1drestricted T cells in 2004 [15]. M. Tb contains phosphatidylmyo-inositol (PI) and $\mathrm{PIM}_{1}-\mathrm{PIM}_{6}$, the most abundant being $\mathrm{PIM}_{2}$ and $\mathrm{PIM}_{6}$ (Figure 9). In 1963, Ballou and colleagues characterised PIMs and deduced that, in $\mathrm{PIM}_{1}$ the inositol residue of $\mathrm{PI}$ is mannosylated at the $\mathrm{C}-2$ position, while, in $\mathrm{PIM}_{2}, \mathrm{PIM}_{1}$ is further mannosylated at the C-6 position of the inositol moiety. Further $\alpha(1-6)$ mannosylation of $\mathrm{PIM}_{2}$ gives rise to PIM 3 and PIM , and the higher PIM 5 and PIM 6 motifs, which are made by consecutive $\alpha(1-2)$ mannosylation of the $\mathrm{PIM}_{4}$ precursor [57]. 


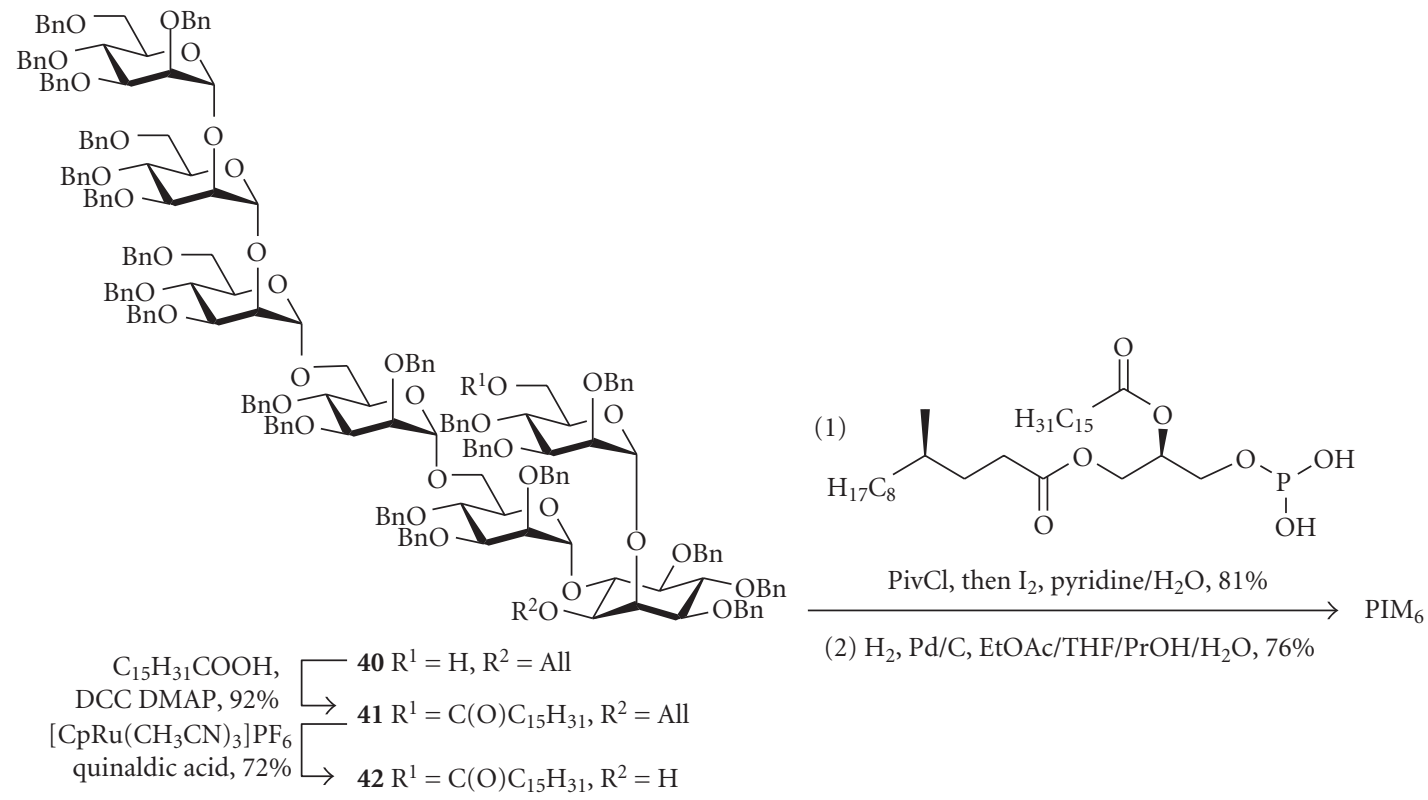

Scheme 6: Synthesis of $\mathrm{PIM}_{6}$.

PIMs stimulate CD1-restricted T cells via CD1d binding and the subsequent triggering of antigen-specific IFN- $\gamma$ and cell-mediated cytotoxicity [15]. The structural requirements for PIMs to bind to CD1d are the possession of two fatty acyl chains and a polar head group [58]. The increased complexity of the carbohydrate moiety does not affect CD1d binding with mycobacterial PI behaving in the same way as $\mathrm{PIM}_{2}$ and $\mathrm{PIM}_{6}$ [58]. Interestingly, the CD1e isoform has been shown to activate lysosomal mannosidases, which break down larger PIM structures, such as $\mathrm{PIM}_{6}$, into $\mathrm{PIM}_{2}$ that is then presented by CD1d [59]. PIM ether analogues are also effective in enhancing IL-12 production by immature bovine dendritic cells and thus have the potential to be used as an adjuvant [60]. The first total synthesis of the more complex PIM $_{6}$ was reported in 2006 by Liu and coworkers [61]. Pseudoheptasaccharide 40 (Scheme 6) was first acylated and ester 41 subsequently allyl-deprotected to give alcohol 42. Alcohol 42 was then phosphorylated, oxidised, and deprotected to obtain the triacyl PIM $_{6}$.

$\alpha$-Galactosyl ceramides ( $\alpha$ GalCer, 43, Figure 10) were first isolated from the marine sponge Agelas mauritianus in 1993 [62]. Of these, agelasphin-9b (AGL-9b, 43a) and the structurally optimised synthetic $\alpha$-galactosyl ceramide (KRN7000, 43b), now widely known as $\alpha$ GalCer, were found to possess potent antitumour properties. The finding that these molecules formed antigens in $\mathrm{T}$ cell-mediated immunology led to a burst of interest in a class of CD1drestricted T cells known as invariant natural killer T ( $i$ NKT) cells [63]. $\alpha$ GalCer consists of a galactosyl moiety $\alpha$-linked to a ceramide containing a phytosphingosine base and a $\mathrm{C}_{26}$ lipid connected via an amide bond. The phytosphingosine base differs from the sphingosine base found in the endogenous sulfatide glycolipids in that it has an additional hydroxyl at C-4 of the fully saturated lipid backbone.
The antitumour activities of the isolated $43 \mathbf{a}$ and synthetic derivative $\mathbf{4 3 b}$ are comparable; however, as $\mathbf{4 3 b}$ has an extended acyl chain (extra two carbons) and lacks the hydroxyl group on the acyl chain and the methyl branch on the phytosphingosine backbone, the chemical synthesis of $\mathbf{4 3 b}$ is more straightforward and is thus a better drug candidate.

$\alpha$ GalCer has been reported to have potential in the treatment of several diseases including cancer, malaria, type 1 diabetes, and multiple sclerosis [64]. The mechanism by which $\alpha$ GalCer exerts its therapeutic effect only became known with the discovery that it binds to CD1d and activates $i$ NKT cells [65]. $\alpha$ GalCer is the first agonist found to activate the CD1d-restricted $i \mathrm{NKT}$ cells that express an invariant TCR $\alpha$ chain $(\mathrm{V} \alpha 24 \mathrm{~J} \alpha 18$ in humans and $\mathrm{V} \alpha 14 \mathrm{~J} \alpha 18$ in mice). The first chemical synthesis of $\alpha \mathrm{GalCer}$ was reported by Morita et al. [63] in 1995 and subsequently optimised by others in representative syntheses such the use of thioglycoside donor using NIS/TfOH as the promoter system [66] and trichloroacetimidate galactosyl donor using boron trifluoride etherate as the activating agent [67] in the key glycosylation step. Much effort is currently being made to develop derivatives of $\alpha \mathrm{GalCer}$ [68] with improved antitumour activity, particularly within the context of cancer immunotherapy.

3.5. CD1e. Unlike CD1a-d, which are expressed on the cell surface of antigen presenting cells, CDle is primarily found in intracellular compartments (i.e., Golgi apparatus, endosome, and lysosome) and is believed to be crucial for glycolipid processing and loading onto CD1 molecules [59, 69]. In this context, CD1e has been shown to process $\mathrm{PIM}_{6}$ to the smaller PIM 2 motif for presentation by CD1d [59]. 
TABLE 1: Ligands of CD1 molecules.

\begin{tabular}{|c|c|c|c|c|}
\hline CD1 isoform & Endogenous ligand & References & Exogenous ligand & References \\
\hline CD1a & Sulfatide & {$[20,22,23]$} & - & - \\
\hline \multirow{2}{*}{ CD1b } & GM1 & [27-29] & GMM & {$[14,38,39]$} \\
\hline & GQ1b & {$[31,35,37]$} & $\mathrm{Acyl}_{2} \mathrm{SGL}$ & [40-43] \\
\hline $\mathrm{CD} 1 \mathrm{c}$ & MPD & [45-47] & MPM & [48-52] \\
\hline \multirow{2}{*}{ CD1d } & iGb3 & {$[10,54]$} & PIMs & {$[15,56-61]$} \\
\hline & Sulfatide & [20-23] & $\alpha$-GalCer & [62-68] \\
\hline $\mathrm{CD} 1 \mathrm{e}$ & \multicolumn{3}{|c|}{ Involved in glycolipid antigen presentation } & {$[59,69]$} \\
\hline
\end{tabular}

\section{Concluding Remarks}

Like their protein counterparts, glycolipids can regulate the immune system in a very specific manner via binding to the CD1 family of proteins and subsequent activation of CD1-restricted T cells. Glycolipids that bind to CD1 include both endogenous glycolipids, found within the host, and exogenous glycolipids from foreign materials or pathogens (Table 1). The five members of the CD1 family (CD1ae) show binding specificities to individual or families of glycolipids, and as such, the resulting immune response to each CD1-glycolipid complex can be used for therapies ranging from cancer vaccine adjuvants to the treatment of autoimmune diseases. As more complex biochemical tools are developed, it is almost certain that the role of CD1binding glycolipids in the immune system becomes better understood and opens the gateway to more specific therapies and enhanced preventative vaccination protocols.

\section{Acknowledgments}

The authors would like to thank the Cancer Society of New Zealand (B. L. Stocker) and the Health Research Council of New Zealand (M. S. M. Timmer) for financial support.

\section{References}

[1] R. Pfeiffer, "Untersuchungen über das Choleragift," Zeitschrift für Hygiene und Infektionskrankheiten, vol. 11, no. 1, pp. 393412, 1892.

[2] K. Landsteiner and P. Levine, "On individual differences in human blood," Journal of Experimental Medicine, vol. 47, no. 5, pp. 757-775, 1928.

[3] C. R. H. Raetz and C. Whitfield, "Lipopolysaccharide endotoxins," Annual Review of Biochemistry, vol. 71, pp. 635-700, 2002.

[4] T. J. Painter, W. M. Watkins, and W. T. J. Morgan, "Serologically active fucose-containing oligosaccharides isolated from human blood-group A and B substances," Nature, vol. 206, no. 4984, pp. 594-597, 1965.

[5] F. Calabi, J. M. Jarvis, L. Martin, and C. Milstein, “Two classes of CD1 genes," European Journal of Immunology, vol. 19, no. 2, pp. 285-292, 1989.

[6] D. B. Moody, D. M. Zajonc, and I. A. Wilson, "Anatomy of CD1-lipid antigen complexes," Nature Reviews Immunology, vol. 5, no. 5, pp. 387-399, 2005.

[7] D. B. Moody, B. B. Reinhold, M. R. Guy et al., "Structural requirements for glycolipid antigen recognition by CD1b- restricted T cells," Science, vol. 278, no. 5336, pp. 283-286, 1997.

[8] T. Kawano, J. Cui, Y. Koezuka et al., "CD1d-restricted and TCR-mediated activation of V $(\alpha) 14$ NKT cells by glycosylceramides," Science, vol. 278, no. 5343, pp. 1626-1629, 1997.

[9] T. I. Prigozy, O. Naidenko, P. Qasba et al., "Glycolipid antigen processing for presentation by CD1d molecules," Science, vol. 291, no. 5504, pp. 664-667, 2001.

[10] S. A. Porcelli, "Cutting glycolipids down to size," Nature Immunology, vol. 2, no. 3, pp. 191-192, 2001.

[11] M. Salio, J. D. Silk, and V. Cerundolo, "Recent advances in processing and presentation of CD1 bound lipid antigens," Current Opinion in Immunology, vol. 22, no. 1, pp. 81-88, 2010.

[12] D. Zhou, J. Mattner, C. Cantu et al., "Lysosomal glycosphingolipid recognition by NKT cells," Science, vol. 306, no. 5702, pp. 1786-1789, 2004.

[13] S. Ahmad, "iGb3: to be or not to be?" Nature Reviews Immunology, vol. 7, no. 5, p. 325, 2007.

[14] E. M. Beckman, S. A. Porcelli, C. T. Morita, S. M. Behar, S. T. Furlong, and M. B. Brenner, "Recognition of lipid antigen by CD1-restricted $\alpha \beta+$ T cells," Nature, vol. 372, no. 6507, pp. 691-694, 1994.

[15] K. Fischer, E. Scotet, M. Niemeyer et al., "Mycobacterial phosphatidylinositol mannoside is a natural antigen for CD1d-restricted T cells," Proceedings of the National Academy of Sciences of the United States of America, vol. 101, no. 29, pp. 10685-10690, 2004.

[16] N. A. Parlane, M. Denis, W. B. Severn et al., "Phosphatidylinositol mannosides are efficient mucosal adjuvants," Immunological Investigations, vol. 37, no. 2, pp. 129-142, 2008.

[17] P. A. Sieling, D. Chatterjee, S. A. Porcelli et al., "CD1-restricted T cell recognition of microbial lipoglycan antigens," Science, vol. 269, no. 5221, pp. 227-230, 1995.

[18] J. Mattner, K. L. DeBord, N. Ismail et al., "Exogenous and endogenous glycolipid antigens activate NKT cells during microbial infections," Nature, vol. 434, no. 7032, pp. 525-529, 2005.

[19] D. M. Zajonc, M. A. Elsliger, L. Teyton, and I. A. Wilson, "Crystal structure of CD1a in complex with a sulfatide self antigen at a resolution of $2.15 \AA$," Nature Immunology, vol. 4, no. 8, pp. 808-815, 2003.

[20] A. Shamshiev, H. J. Gober, A. Donda, Z. Mazorra, L. Mori, and G. de Libero, "Presentation of the same glycolipid by different CD1 molecules," Journal of Experimental Medicine, vol. 195, no. 8, pp. 1013-1021, 2002.

[21] D. M. Zajonc, I. Maricic, D. Wu et al., "Structural basis for CD1d presentation of a sulfatide derived from myelin and its implications for autoimmunity," Journal of Experimental Medicine, vol. 202, no. 11, pp. 1517-1526, 2005. 
[22] F. Compostella, L. Franchini, G. De Libero, G. Palmisano, F. Ronchetti, and L. Panza, "CD1a-binding glycosphingolipids stimulating human autoreactive T-cells: synthesis of a family of sulfatides differing in the acyl chain moiety," Tetrahedron, vol. 58, no. 43, pp. 8703-8708, 2002.

[23] L. Franchini, P. Matto, F. Ronchetti et al., "Synthesis and evaluation of human $\mathrm{T}$ cell stimulating activity of an $\alpha$ sulfatide analogue," Bioorganic and Medicinal Chemistry, vol. 15, no. 16, pp. 5529-5536, 2007.

[24] S. D. Gadola, N. R. Zaccai, K. Harlos et al., "Structure of human CDIb with bound ligands at $2.3 \AA$, a maze for alkyl chains," Nature Immunology, vol. 3, no. 8, pp. 721-726, 2002.

[25] D. B. Moody, V. Briken, T. Y. Cheng et al., "Lipid length controls antigen entry into endosomal and nonendosomal pathways for CD1b presentation," Nature Immunology, vol. 3, no. 5, pp. 435-442, 2002.

[26] A. J. Steck, A. K. Stalder, and S. Renaud, "Anti-myelinassociated glycoprotein neuropathy," Current Opinion in Neurology, vol. 19, no. 5, pp. 458-463, 2006.

[27] A. Shamshiev, A. Donda, T. I. Prigozy et al., "The $\alpha \beta$ T cell response to self-glycolipids shows a novel mechanism of CD1b loading and a requirement for complex oligosaccharides," Immunity, vol. 13, no. 2, pp. 255-264, 2000.

[28] M. Sugimoto, M. Numata, K. Koike, Y. Nakahara, and T. Ogawa, "Total synthesis of gangliosides GM1 and GM2," Carbohydrate Research, vol. 156, pp. C1-C5, 1986.

[29] S. K. Bhattacharya and S. J. Danishefsky, "A total synthesis of the methyl glycoside of ganglioside GM1," Journal of Organic Chemistry, vol. 65, no. 1, pp. 144-151, 2000.

[30] A. Shamshiev, A. Donda, I. Carena, L. Mori, L. Kappos, and G. De Libero, "Self glycolipids as T-cell autoantigens," European Journal of Immunology, vol. 29, no. 5, pp. 1667-1675, 1999.

[31] H. K. Ishida, H. Ishida, M. Kiso, and A. Hasegawa, "Total synthesis of ganglioside GQ1b," Carbohydrate Research, vol. 260, no. 2, pp. C1-C6, 1994.

[32] R. Kuhn and H. Wiegandt, "Die Konstitution der Ganglio-Ntetraose und des Gangliosids $\mathrm{G}_{I}$," Chemische Berichte, vol. 96, pp. 866-880, 1963.

[33] S. Ando and R. K. Yu, "Isolation and characterization of two isomers of brain tetrasialogangliosides," Journal of Biological Chemistry, vol. 254, no. 23, pp. 12224-12229, 1979.

[34] P. Fredman, J. E. Mansson, L. Svennerholm, K. A. Karlsson, I. Pascher, and B. E. Samuelsson, "The structure of the tetrasialoganglioside from human brain," FEBS Letters, vol. 110, no. 1, pp. 80-84, 1980.

[35] A. Imamura, H. Ando, H. Ishida, and M. Kiso, "Ganglioside GQ1b: efficient total synthesis and the expansion to synthetic derivatives to elucidate its biological roles," Journal of Organic Chemistry, vol. 74, no. 8, pp. 3009-3023, 2009.

[36] S. Ando, M. Isobe, and Y. Nagai, "High performance preparative column chromatography of lipids using a new porous silica, Iatrobeads. I. Separation of molecular species of sphingoglycolipids," Biochimica et Biophysica Acta, vol. 424, no. 1, pp. 98-105, 1976.

[37] N. Kanda and S. Watanabe, "Gangliosides GD1b, GT1b, and GQ1b enhance IL-2 and IFN- $\gamma$ production and suppress IL-4 and IL-5 production in phytohemagglutinin-stimulated human T cells," Journal of Immunology, vol. 166, no. 1, pp. 7280, 2001.

[38] W. A. Ernst, J. Maher, S. Cho et al., "Molecular interaction of CD1b with lipoglycan antigens," Immunity, vol. 8, no. 3, pp. 331-340, 1998.
[39] T. Batuwangala, D. Shepherd, S. D. Gadola et al., "The crystal structure of human CD1b with a bound bacterial glycolipid," Journal of Immunology, vol. 172, no. 4, pp. 2382-2388, 2004.

[40] M. Gilleron, S. Stenger, Z. Mazorra et al., "Diacylated sulfoglycolipids are novel Mycobacterial antigens stimulating CD1-restricted T cells during infection with Mycobacterium tuberculosis," Journal of Experimental Medicine, vol. 199, no. 5, pp. 649-659, 2004.

[41] M. B. Goren, O. Brokl, B. C. Das, and E. Lederer, "Sulfolipid I of Mycobacterium tuberculosis, strain H37RV. Nature of the acyl substituents," Biochemistry, vol. 10, no. 1, pp. 72-81, 1971.

[42] J. Guiard, A. Collmann, M. Gilleron et al., "Synthesis of diacylated trehalose sulfates: candidates for a tuberculosis vaccine," Angewandte Chemie_International Edition, vol. 47, no. 50, pp. 9734-9738, 2008.

[43] J. Guiard, A. Collmann, L. F. Garcia-Alles et al., "Fatty acyl structures of Mycobacterium tuberculosis sulfoglycolipid govern T cell response," Journal of Immunology, vol. 182, no. 11, pp. 7030-7037, 2009.

[44] D. Garzón, P. J. Bond, and J. D. Faraldo-Gómez, "Predicted structural basis for $\mathrm{CD} 1 \mathrm{c}$ presentation of mycobacterial branched polyketides and long lipopeptide antigens," Molecular Immunology, vol. 47, no. 2-3, pp. 253-260, 2009.

[45] D. B. Moody, T. Ulrichs, W. Mühlecker et al., "CD1c-mediated T-cell recognition of isoprenoid glycolipids in Mycobacterium tuberculosis infection," Nature, vol. 404, no. 6780, pp. 884-888, 2000.

[46] J. F. Pennock, F. W. Hemming, and R. A. Morton, "Dolichol: a naturally occurring isoprenoid alcohol," Nature, vol. 186, no. 4723, pp. 470-472, 1960.

[47] P. Low, G. Dallner, S. Mayor, S. Cohen, B. T. Chait, and A. K. Menon, "The mevalonate pathway in the bloodstream form of Trypanosoma brucei. Identification of dolichols containing 11 and 12 isoprene residues," Journal of Biological Chemistry, vol. 266, no. 29, pp. 19250-19257, 1991.

[48] I. Matsunaga, A. Bhatt, D. C. Young et al., "Mycobacterium tuberculosis pks12 produces a novel polyketide presented by CD1c to T cells," Journal of Experimental Medicine, vol. 200, no. 12, pp. 1559-1569, 2004.

[49] A. de Jong, E. C. Arce, T. Y. Cheng et al., "CD1c presentation of synthetic glycolipid antigens with foreign Alkyl branching motifs," Chemistry and Biology, vol. 14, no. 11, pp. 1232-1242, 2007.

[50] D. Crich and V. Dudkin, "Confirmation of the connectivity of 4,8,12,16,20-pentamethylpentacosylphoshoryl $\beta$ D-mannopyranoside, an unusual $\beta$-mannosyl phosphoisoprenoid from Mycobacterium avium, through synthesis," Journal of the American Chemical Society, vol. 124, no. 10, pp. 2263-2266, 2002.

[51] R. P. Van Summeren, D. B. Moody, B. L. Feringa, and A. J. Minnaard, "Total synthesis of enantiopure $\beta$-D-mannosyl phosphomycoketides from Mycobacterium tuberculosis," Journal of the American Chemical Society, vol. 128, no. 14, pp. 4546-4547, 2006.

[52] K. Hiromatsu, C. C. Dascher, K. P. LeClair et al., "Induction of CD1-restricted immune responses in guinea pigs by immunization with mycobacterial lipid antigens," Journal of Immunology, vol. 169, no. 1, pp. 330-339, 2002.

[53] D. M. Zajonc and M. Kronenberg, "CD1 mediated T cell recognition of glycolipids," Current Opinion in Structural Biology, vol. 17, no. 5, pp. 521-529, 2007.

[54] D. Qiu and R. R. Schmidt, "Glycosyl imidates, 52. Synthesis of Globotriaosylceramide (Gb3) and Isoglobotriaosylceramide 
(isoGb3)," Liebigs Annalen der Chemie, vol. 1993, no. 3, pp. 217-224, 1992.

[55] N. Yin, X. Long, R. D. Goff et al., "Alpha anomers of iGb3 and Gb3 stimulate cytokine production by natural killer T cells," ACS Chemical Biology, vol. 4, no. 3, pp. 191-197, 2009.

[56] R. J. Anderson, "The chemistry of the lipoids of tubercle bacilli. XIV. The occurrence of inosite in the phosphatide from human tubercle bacilli," Journal of the American Chemical Society, vol. 52, no. 4, pp. 1607-1608, 1930.

[57] C. E. Ballou, E. Vilkas, and E. Lederer, "Structural studies on the myo-inositol phospholipids of Mycobacterium tuberculosis (var. bovis, strain BCG)," Journal of Biological Chemistry, vol. 238, no. 1, pp. 69-76, 1963.

[58] M. Gilleron, C. Ronet, M. Mempel, B. Monsarrat, G. Gachelin, and G. Puzo, "Acylation state of the phosphatidylinositol mannosides from Mycobacterium bovis Bacillus Calmette Guérin and ability to induce granuloma and recruit natural killer T cells," Journal of Biological Chemistry, vol. 276, no. 37, pp. 34896-34904, 2001.

[59] H. De La Salle, S. Mariotti, C. Angenieux et al., "Immunology: assistance of microbial glycolipid antigen processing by CD1e," Science, vol. 310, no. 5752, pp. 1321-1324, 2005.

[60] G. D. Ainge, N. A. Parlane, M. Denis et al., "Phosphatidylinositol mannoside ether analogues: ayntheses and interleukin-12inducing properties," Journal of Organic Chemistry, vol. 72, no. 14, pp. 5291-5296, 2007.

[61] X. Liu, B. L. Stocker, and P. H. Seeberger, "Total synthesis of phosphatidylinositol mannosides of Mycobacterium tuberculosis," Journal of the American Chemical Society, vol. 128, no. 11, pp. 3638-3648, 2006.

[62] T. Natori, Y. Koezuka, and T. Higa, "Agelasphins, novel $\alpha$ galactosylceramides from the marine sponge Agelas mauritianus," Tetrahedron Letters, vol. 34, no. 35, pp. 5591-5592, 1993.

[63] M. Morita, K. Motoki, K. Akimoto et al., "Structure-activity relationship of $\alpha$-galactosylceramides against b16- bearing mice," Journal of Medicinal Chemistry, vol. 38, no. 12, pp. 2176-2187, 1995.

[64] L. Van Kaer, " $\alpha$-galactosylceramide therapy for autoimmune diseases: prospects and obstacles," Nature Reviews Immunology, vol. 5, no. 1, pp. 31-42, 2005.

[65] D. I. Godfrey and S. P. Berzins, "Control points in NKT-cell development," Nature Reviews Immunology, vol. 7, no. 7, pp. 505-518, 2007.

[66] G. T. Fan, Y. S. Pan, K. C. Lu et al., "Synthesis of $\alpha$-galactosyl ceramide and the related glycolipids for evaluation of their activities on mouse splenocytes," Tetrahedron, vol. 61, no. 7, pp. 1855-1862, 2005.

[67] O. Plettenburg, V. Bodmer-Narkevitch, and C. H. Wong, "Synthesis of $\alpha$-galactosyl ceramide, a potent immunostimulatory agent," Journal of Organic Chemistry, vol. 67, no. 13, pp. 45594564, 2002.

[68] D. Wu, M. Fujio, and C. H. Wong, "Glycolipids as immunostimulating agents," Bioorganic and Medicinal Chemistry, vol. 16, no. 3, pp. 1073-1083, 2008.

[69] C. Angénieux, V. Fraisier, B. Maître et al., "The cellular pathway of CD1e in immature and maturing dendritic cells," Traffic, vol. 6, no. 4, pp. 286-302, 2005. 


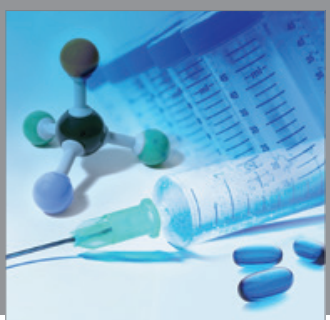

International Journal of

Medicinal Chemistry

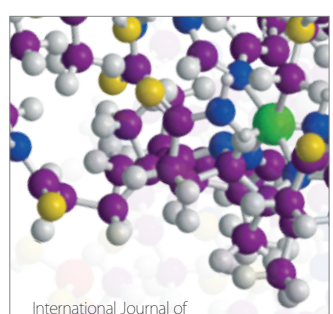

Carbohydrate Chemistry

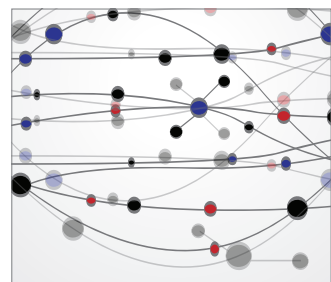

The Scientific World Journal
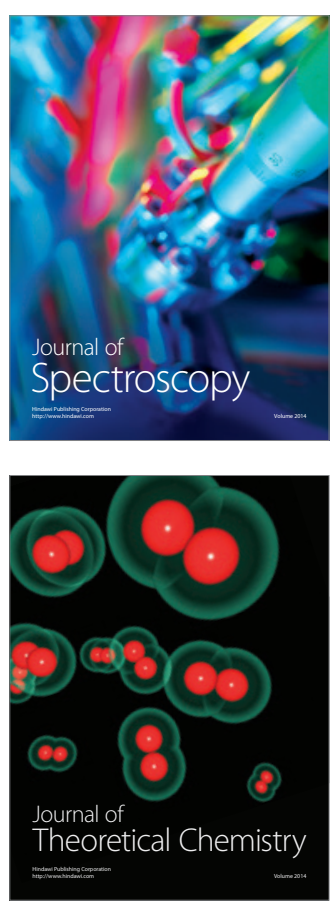
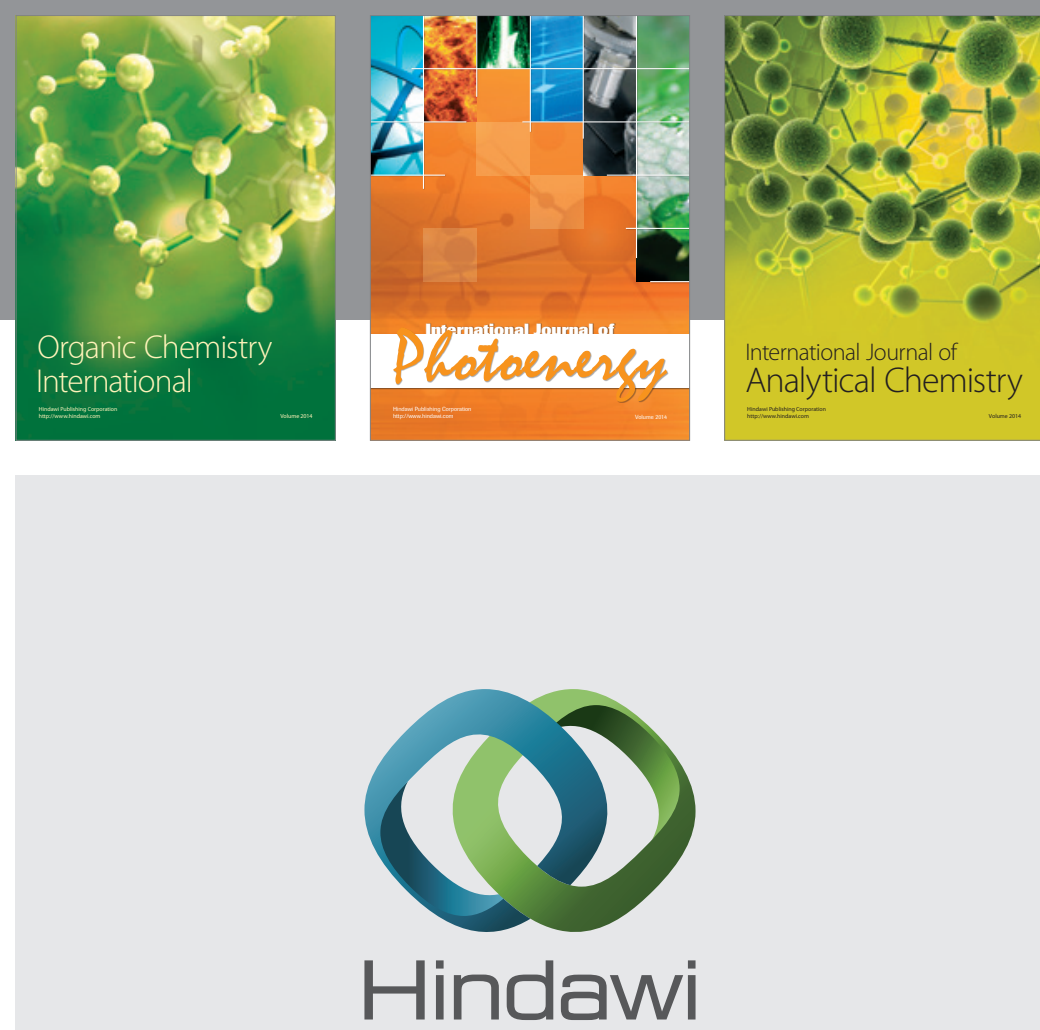

Submit your manuscripts at

http://www.hindawi.com
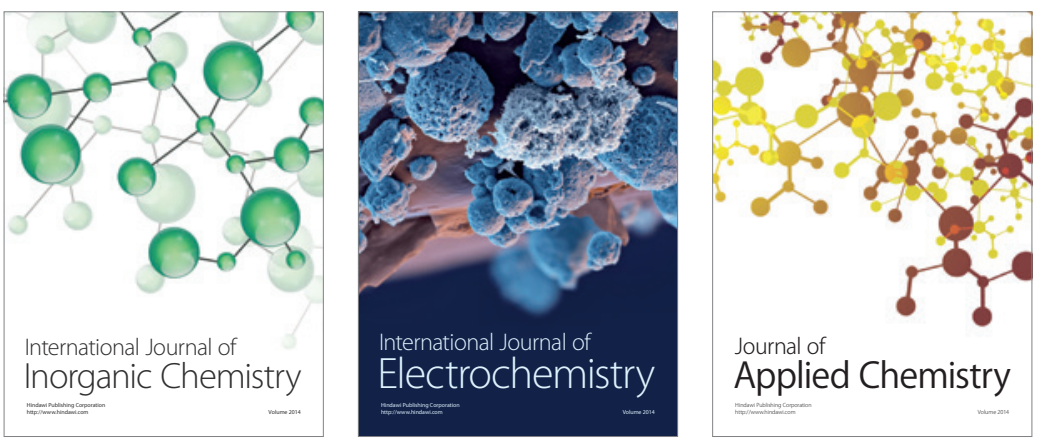

Journal of

Applied Chemistry
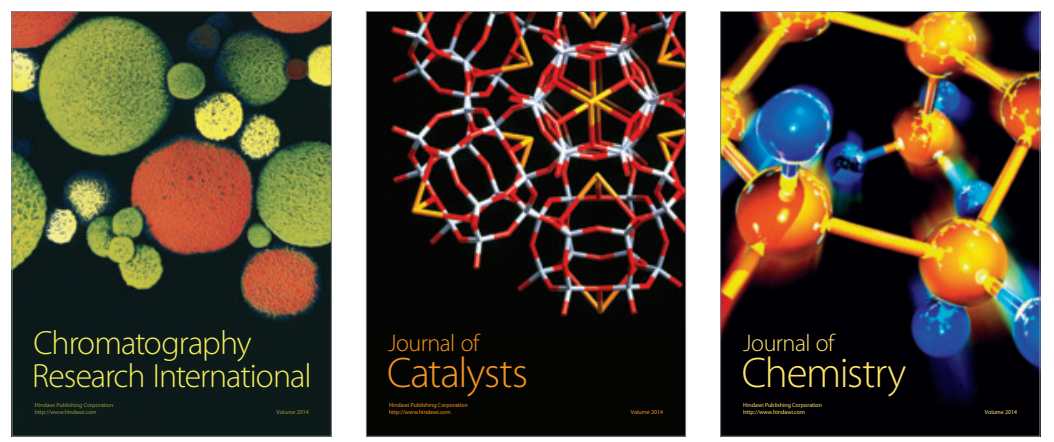
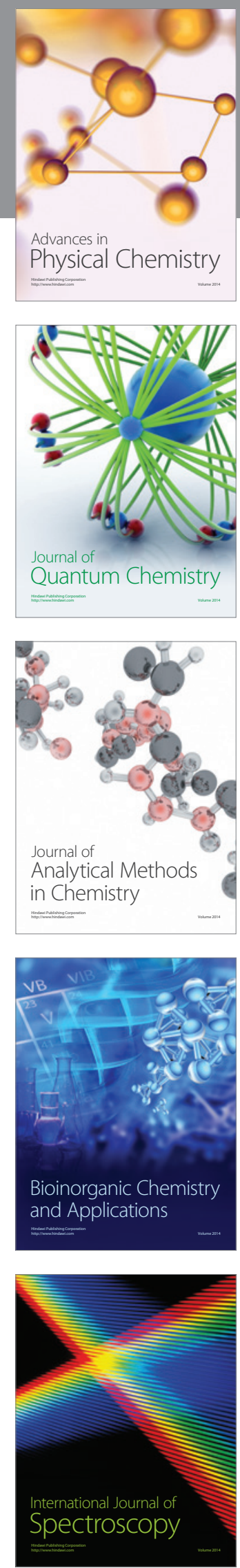